OPEN ACCESS

Edited by:

Paulo José Pereira Lima Teixeira,

University of São Paulo, Brazil

Reviewed by: Monica Calvo-Polanco,

University of Salamanca, Spain

Manuel G. M. Mota,

University of Evora, Portugal

Atsushi Watanabe,

Kyushu University, Japan

*Correspondence:

Young-Su Seo

yseo0000@gmail.com

Jin-Cheol Kim

kjinc@jnu.ac.kr

${ }^{\dagger}$ These authors have contributed equally to this work

Specialty section: This article was submitted to Plant Pathogen Interactions,

a section of the journa Frontiers in Plant Science

Received: 17 April 2020 Accepted: 22 June 2020 Published: 08 July 2020

Citation:

Park AR, Jeong S-I, Jeon HW, Kim J, Kim N, Ha MT, Mannaa M, Kim J, Lee CW, Min BS, Seo Y-S and Kim J-C (2020) A Diketopiperazine, Cyclo-(L-Pro-L-Ile), Derived From Bacillus thuringiensis JCK-1233 Controls Pine Wilt Disease by Elicitation of Moderate Hypersensitive Reaction.

Front. Plant Sci. 11:1023. doi: 10.3389/fpls.2020.01023

\section{A Diketopiperazine, Cyclo-(L-Pro-L-Ile), Derived From Bacillus thuringiensis JCK-1233 Controls Pine Wilt Disease by Elicitation of Moderate Hypersensitive Reaction}

\author{
Ae Ran Park ${ }^{1 \dagger}$, Se-In Jeong ${ }^{1 \dagger}$, Hee Won Jeon ${ }^{1}$, Jueun Kim ${ }^{2}$, Namgyu Kim $^{3}$, \\ Manh Tuan $\mathrm{Ha}^{4}$, Mohamed Mannaa ${ }^{3}$, Junheon Kim ${ }^{5}$, Chul Won Lee ${ }^{2}$, Byung Sun Min ${ }^{4}$, \\ Young-Su Seo ${ }^{3 *}$ and Jin-Cheol Kim ${ }^{1 *}$ \\ ${ }^{1}$ Department of Agricultural Chemistry, College of Agriculture and Life Sciences, Institute of Environmentally Friendly \\ Agriculture, Chonnam National University, Gwangju, South Korea, ${ }^{2}$ Department of Chemistry, Chonnam National \\ University, Gwangju, South Korea, ${ }^{3}$ Department of Integrated Biological Science, College of Natural Science, Pusan \\ National University, Busan, South Korea, ${ }^{4}$ Drug Research and Development Center, College of Pharmacy, Daegu \\ Catholic University, Gyeongbuk, South Korea, ${ }^{5}$ Forest Insect Pests and Diseases Division, National Institute of Forest \\ Science, Seoul, South Korea
}

Pine wilt disease (PWD) caused by the pine wood nematode (PWN) Bursaphelenchus xylophilus is one of the devastating diseases affecting pine forests worldwide. Although effective control measurements are still missing, induction of resistance could represent a possible eco-friendly alternative. In this study, induced resistance-based in vitro and in vivo screening tests were carried out for selection of bacteria with the ability to suppress PWD. Out of 504 isolated bacteria, Bacillus thuringiensis JCK-1233 was selected for its ability to boost pathogenesis-related 1 (PR1) gene expression, a marker of systemic acquired resistance. Moreover, treatment of pine seedlings with $B$. thuringiensis JCK1233 resulted in increased expression of other defense-related genes, and significantly inhibited PWD development under greenhouse conditions. However, B. thuringiensis JCK-1233 showed no direct nematicidal activity against B. xylophilus. To identify the effective compound responsible for the induction of resistance in $B$. thuringiensis JCK1233, several diketopiperazines (DPKs) including cyclo-(D-Pro-L-Val), cyclo-(L-Pro-L-Ile), cyclo-(L-Pro-L-Phe), and cyclo-(L-Leu-L-Val) were isolated and tested. Foliar treatment of pine seedlings with Cyclo-(L-Pro-L-lle) resulted in suppression of PWD severity and increased the expression of defense-related genes similarly to $B$. thuringiensis JCK-1233 treatment. Interestingly, treatment with $B$. thuringiensis JCK-1233 or cyclo-(L-Pro-L-Ile) showed moderately enhanced expression of $P R-1, P R-2, P R-3, P R-4, P R-5$, and $P R-9$ genes following inoculation with PWN compared to that in the untreated control, indicating that they mitigated the burst of hypersensitive reaction in susceptible pine seedlings. In contrast, they significantly increased the expression levels of PR-6 and PR-10 before 
PWN inoculation. In conclusion, foliar spraying with either B. thuringiensis JCK-1233 culture suspension or DPKs could induce resistance in pine seedlings, thereby alleviating the serious damage by PWD. Taken together, this study supports aerial spraying with eco-friendly biotic or abiotic agents as a valuable strategy that may mark an epoch for the control of PWD in pine forests.

Keywords: pine wood nematodes, diketopiperazine, resistance-inducing bacteria, foliar application, moderate hypersensitive reaction, cyclo-(L-Pro-L-Ile), Bacillus thuringiensis

\section{INTRODUCTION}

Pine wilt disease (PWD) caused by the pine wood nematode (PWN) Bursaphelenchus xylophilus is one of the most destructive diseases damaging pine forests. The transmission of PWN occurs via pine sawyer beetles (Monochamus spp.), which are attracted to pine trees for feeding or oviposition (Mamiya and Enda, 1972). Since the first incidence of PWD was reported in 1905 in Nagasaki, Japan (Yano, 1913), PWD has spread quickly throughout East Asia, Europe, and even North America, threatening pine forests worldwide (Yi et al., 1989; Mota et al., 1999).

Despite the advances in the study of PWD, effective control measures have not yet been developed. As the habitat of pine trees is very wide areas and, in many cases, poorly accessible, such as cliffs and steep mountains, operations by manual labor are impractical. In addition, most pine trees infected by PWN are killed rapidly, as PWN is an endoparasite that is very difficult to control. Consequentially, PWD has caused enormous economic losses with environmental impacts worldwide and thus, is considered a serious threat to be dealt with (Tóth, 2011).

Current PWD control methods depend mainly on the removal of infection sources or other preventative measures, such as fumigation, burning, clear-cutting, breeding, aerial insecticide spraying, and trunk injection (Takai et al., 2003; Kwon et al., 2005; Nose and Shiraishi, 2008; Bonifácio et al., 2014). However, traditional chemical control using chemical compounds, including methyl bromide and phosphine, is known to cause severe environmental problems because of the high toxicity and potential to induce resistance among parasitic nematodes (Bell, 2000). Recently, with the growing public interest in eco-friendly control methods, biological control agents of plant-parasitic nematodes have received greater attention as an environmentally safe alternative for plant protection. Specifically, agricultural application of plant-associated bacteria, originated from phyllosphere or rhizosphere, exhibited the ability to reduce the incidence or severity of soil-borne diseases (Vallad and Goodman, 2004). Induced resistance is among the reported biocontrol mechanisms for management of diseases that do not exert a direct selective pressure on the pathogen population. Specifically, systemic acquired resistance (SAR) is activated throughout higher plants after being exposed to elicitors from virulent, avirulent, or nonpathogenic microbes, or chemical stimuli such as salicylic acid (SA), which then confers long-lasting protection against a broad spectrum of phytopathogenic microorganisms (Vallad and Goodman, 2004).
Studies on plant immunity have indicated that endophytic bacteria increase plant resistance to pathogens through signaling crosstalk in various plants. However, few studies have addressed the use of bacteria-mediated induction of resistance for PWD management. Previously, inoculation with avirulent B. xylophilus was shown to induce resistance against PWD in pine trees, suggesting that the mechanism of induced resistance in pine trees has the potential for biological control against PWD (Kosaka et al., 2001). Interestingly, foliar sprays of SAR inducers in pineapple reduced the reproduction of plant-parasitic nematodes such as Meloidogyne javanica and Rotylenchulus reniformis, which damage the pineapple root system (Rohrbach and Apt, 1986; Chinnasri et al., 2006). Some rhizobacteria also elicit systemic resistance that may be dependent on SA (Kloepper and Ryu, 2006). It was reported that even though susceptible pine trees are infected with virulent PWNs by vector beetles feeding, the ability of pine trees to activate defensive responses to the infection may reduce the nematode migration and proliferation rates within the plant tissues to some extent (Kuroda, 2008). Therefore, we predicted that the induction of resistance by foliar application with biological agents, such as endophytic bacteria, could suppress the dispersal of PWN and limit the serious damage caused by PWD.

The induced resistance in plants is divided into systemic acquired resistance (SAR) and induced systemic resistance (ISR) (Van Loon et al., 1998). Although SAR is induced by a prior pathogen infection at a local tissue, it can protect the rest of the plant from a second infection. ISR is elicited by plant growthpromoting rhizobacteria (PGPR) and confers protection of plants to a broad spectrum of attackers. SAR is associated with the SA signaling pathway, whereas ISR is mediated by the JA and ET signaling pathways. Although it has been known that SAR and ISR are clearly different, recent studies have been reported that they are interconnected by crosstalk of SA, ET, and jasmonic acid signaling from some rhizospheric Bacillus strains (Niu et al., 2016; Song et al., 2017). For example, PGPR Bacillus cereus AR156 installs ISR and enhances SAR with increased PR-1 protein expression in plants (Niu et al., 2016). Pathogenesisrelated (PR) genes are widely expressed downstream the SA, jasmonic acid (JA), and ethylene (ET) pathways in plants, which play important roles in the inducible defense mechanism in plants against pathogens, facilitating plant adaptation to the environment (Hoffmann-Sommergruber, 2002). Specifically, the $P R-1$ gene is used as a marker for the SA-dependent signal transduction pathway and for the study of defense gene expression in plants (Ono et al., 2004). Therefore, transgenic 
Arabidopsis plants transformed with the $P R$-1-promoter fused to the $\beta$-glucuronidase (GUS) or luciferase have been used as a model system for high-throughput screening of bacterial activators that enhance disease-resistance mechanisms in various plants (Ogura et al., 2005; Narusaka et al., 2006). Therefore, we predicted that endophytic bacteria may stimulate the expression of the $P R-1$ gene and influence their resistanceinducing activities.

In this study, endophytic bacteria isolated from several sources were screened for their possible induction of resistance against PWD, using a sequence of Arabidopsis plants with the $P R$-1-promoter fused to GUS, in vitro pine callus, and in vivo pine seedling assay systems. The objectives of this study were to select resistance-inducing bacteria capable of managing PWD by foliar application, identify the bioactive compounds responsible for the induction of resistance, and characterize the functional mechanism employed in pine trees by the selected bacteria and their bioactive compounds.

\section{MATERIALS AND METHODS}

\section{Nematodes, Plant Materials, and Callus Culture}

The pine wood nematode (PWN) B. xylophilus was isolated from infected pine trees and provided by the National Institute of Forest Science (NIFoS; Seoul, South Korea). Initially, PWN was cultured on the mycelia of Botrytis cinerea fully grown on potato dextrose agar (PDA, Difco; Becton, Dickinson and Company, $\mathrm{MD}, \mathrm{USA}$ ) at $25^{\circ} \mathrm{C}$ for propagation (Maehara and Futai, 2000). After 7 days of incubation, the propagated nematode was harvested using the funnel technique (Baermann, 1917), rinsed three times with sterilized distilled water and then prepared as an aqueous suspension of $B$. xylophilus for subsequent experiments.

Seeds of the Arabidopsis plant (Arabidopsis thaliana ecotype Columbia (Col-0)) genetically engineered with the GUS reporter gene fused to the $P R-1$ promoter were provided by Y. C. Kim (College of Agriculture and Life Science, Chonnam National University, South Korea). The seeds were surface sterilized in 5\% sodium hypochlorite followed by immersion for $3 \mathrm{~min}$ in $70 \%$ ethanol. After washing with sterile distilled water, they were left to imbibe in sterile water containing $0.1 \%$ agarose (Gibco; Thermo Fisher Scientific INc., MA, USA) in the dark at 4 for 3 days. Subsequently, the seeds were allowed to germinate on plates containing $1 \times$ Murashige and Skoog (MS) salt mixture and $0.5 \mathrm{~g} / \mathrm{L} 2$-(N-morpholino) ethanesulfonic acid (MES), $\mathrm{pH} 5.8$, in $1 \%$ Duchefa agar (Duchefa Biochemie, Haarlem, The Netherlands). Seedlings were grown in a growth chamber (VS3DM-600; Hanbaek, Bucheon, South Korea) under photoperiodic cycles of 16-hour light/8-hour dark at 22 with $70 \%$ humidity.

For the in vivo pathogenicity assay, three- or four-year old red pine (Pinus densiflora) and black pine ( $P$. thunbergii) saplings with average height of $40 \mathrm{~cm}$ and average diameter of $0.5 \mathrm{~cm}$ were obtained from Daelim Farm (Okcheon, South Korea) and then transplanted to $15-\mathrm{cm}$ diameter pots containing sterilized nursery soil in the greenhouse, keeping an average temperature of $25^{\circ} \mathrm{C}$.

For the in vitro assay, Pinus calli were obtained from NIFoS (Seoul, South Korea). Calli were taken aseptically from embryos of $P$. densiflora and cultured in Litvay medium (LM; Thomas Scientific Inc., NJ, USA), including vitamins with $2 \mu \mathrm{g} / \mathrm{ml} 2,4-$ chlorophenoxyacetic acid and $1 \mu \mathrm{g} / \mathrm{ml}$ 6-benzyl-aminopurine solution at 24 under dark conditions.

\section{Isolation and Incubation of Endophytic Bacteria}

Endophytic strains were isolated from agronomic plants and grove trees of five regions in South Korea (Daejeon, Gwangju, Jeongeup, Busan, and Sacheon). The agronomic plants tested were tomato, pepper, and onion. The grove trees used in this study included cherry and peach trees. Individual leave, stem, and root samples were put into plastic bags, placed in a cool box for transportation, and stored at $4^{\circ} \mathrm{C}$. Plant samples were surface sterilized for $10 \mathrm{~s}$ with $2 \%$ sodium hypochlorite and rinsed five times in sterile distilled water. Sterilized plant samples were dissected into $1-\mathrm{cm}$ pieces and macerated with a sterile mortar and pestle. Each $1 \mathrm{~g}$ plant sample was suspended in $10 \mathrm{ml}$ of sterile distilled water and shaken vigorously for $2 \mathrm{~min}$. The supernatant was serially diluted in sterile distilled water $\left(10^{-1}\right.$ to $10^{-7}$ ), and plated on tryptic soy agar medium (TSA, Difco, MD, USA). After incubation at $30^{\circ} \mathrm{C}$ for 1-2 days, each strain was streaked on TSA and then a single colony was isolated. Isolated bacterial strains were stored cryogenically in $20 \%$ glycerol at $-70^{\circ} \mathrm{C}$. For in vitro and in vivo bioassays, bacterial strains were inoculated in tryptic soy broth (TSB, Difco, MD, USA) for 3 days at $30^{\circ} \mathrm{C}$ with agitation $(200 \mathrm{rpm})$.

\section{Histochemical Staining for GUS Activity in Arabidopsis Leaves}

Four-week-old Arabidopsis seedlings from the PR-1pro::GUS line were used to assess the resistance inducting activity of endophytic bacteria, which were isolated from several plants and their rhizospheric soils. For GUS staining of Arabidopsis leaves, leaf discs (5 mm diameter) were placed in 96 well plates containing the culture filtrate of bacterial strains and then the plates were incubated for $12 \mathrm{~h}$ at 22 with relative humidity above $70 \%$ under light conditions. After treatment, GUS activity was measured as described by Jefferson et al. (1987). Prior to the staining reactions, the treated leaves were fixed in a fixation solution $(0.3 \%$ formaldehyde, $10 \mathrm{mM}$ MES, pH 5.6, and $0.3 \mathrm{M}$ mannitol) for $1 \mathrm{~h}$ on ice. The staining reaction was performed in $50 \mathrm{mM}$ sodium phosphate buffer ( $\mathrm{pH} 7.0$ ) that contained $10 \mathrm{mg} /$ $\mathrm{ml} 5$-bromo-4-chloro-3-indolyl- $\beta{ }_{-}{ }_{\mathrm{D}}$-glucuronic acid (X-Gluc) and $0.02 \%(\mathrm{w} / \mathrm{v})$ Triton $\mathrm{X}-100$ for $24 \mathrm{~h}$ at 22 in the dark. After staining, leaf discs were decolorized in $7 \%(\mathrm{v} / \mathrm{v})$ ethanol for $24 \mathrm{~h}$ and rinsed with water. Each experiment was run in triplicates. 


\section{In Vitro Screening of Bacterial Strains That Induce PR-1 Gene in Pinus callus}

The endophytic bacteria that were selected based on GUS activity in PR-1pro::GUS Arabidopsis line were used for the in vitro assay that analyzed their $P R-1$ gene expression inducing activity in Pinus callus. Selected endophytic bacteria were cultured up to an $\mathrm{OD}_{600}=0.8$ at 30 in TSB for the in vitro assay. A bacterial suspension $(500 \mu \mathrm{l})$ was treated with $P$. densiflora callus (100 mg) and then incubated at 24 using a digital rocker at $50 \mathrm{rpm}$ under dark conditions. The untreated controls for the in vitro experiments were performed applying the same amount of sterile TSB. Each experiment was run in triplicates.

After incubation with the bacterial suspension for 1 day, total P. densiflora callus RNA was extracted using CTAB extraction buffer with elimination of high viscosity and excessive polysaccharides (Azevedo et al., 2003). Then, total RNA was further purified using RNeasy mini kit (Qiagen, Valencia, CA, USA), according to the manufacturer's recommendations. cDNA libraries were prepared from total callus RNA with oligo (dT) primers and SuperScript ${ }^{\mathrm{TM}}$ IV reverse transcriptase (Invitrogen Inc., Carlsbad, CA, USA), according to the manufacturer's protocols. The PCR primers of the $P R-1$ gene used in this study (Table 1) were synthesized by Genotech (Daejeon, Korea).

Determination of relative mRNA expression was carried out in a real-time PCR detection system (Bio-Rad CFX 96; Bio-Rad Laboratories, Hercules, CA, USA). cDNA was analyzed using $\mathrm{iQ}^{\mathrm{TM}}$ SYBR Green supermix (Bio-Rad Laboratories) in a $20 \mu \mathrm{l}$ volume. Data were analyzed using BioRad CFX Manager Version 2.1. Relative fold changes in mRNA between treatments were determined based on the $\Delta \Delta \mathrm{CT}$ method after normalizing to the housekeeping gene elongation factor $1 \alpha$ (EF-1 $\alpha$ ) (Livak and Schmittgen, 2001). Samples were run in triplicate and averaged.

TABLE 1 | Primers used in this study.

\begin{tabular}{lll}
\hline Gene & \multicolumn{1}{c}{ Sequence (5' $\rightarrow$ 3') } & Reference \\
\hline PR-1 For & TGCCCCTTCAGGTAAATCGT & Hirao et al. (2012) \\
PR-1 Rev & GCGGGTCGTAGTTGCAGATAA & \\
PR-2 For & CGACAACATTCGCCCCTTCT \\
PR-2 Rev & CTGCAGCGCGGTTGAATAT \\
PR-3 For & CCATCGAAGCCCAGGTAATT \\
PR-3 Rev & AGCCGGGAAGCAATATTATGT \\
PR-4 For & CCCCGTTACTGTCAATTGCAT \\
PR-4 Rev & AAAGCGTGACGGTGCGTATT \\
PR-5 For & GAACCAGTGCCCATACACAGTCT \\
PR-5 Rev & CCTGCGGCAACGTTAAAAGTC \\
PR-6 For & TGCTGGCGGCATCTATTTA \\
PR-6 Rev & TAACACCTGCGCAAATGCA \\
PR-9 For & ACACCACCGTGCTGGACATT \\
PR-9 Rev & GTGCGGGAGTCGGTGTAGAG \\
PR-10 For & TGTCTCAAGTGGAGGCAAGGA \\
PR-10 Rev & AAGCGACAATTCAGGCAAAAC \\
EF-1 $\alpha$ For & GGGAAGCCACCCAAAGTIT \\
EF-1 $\alpha$ Rev & TACATGGGAAGACGCCGAAT \\
PdPR-4 For & TGTGACGAATCCTTCAACGC \\
PdPR-4 Rev & AAAGCCGCGGTTCAAGATC \\
PdCHI For & TTCATCACAGCTGCCAATGC \\
PdCHI Rev & ATGCTCCAGTTCGTGCATC \\
PdBGL2 For & AAGTCCGTGCATTCTCAACG \\
PdBGL2 Rev & TCCGCCATGGAAATTTGGG & \\
&
\end{tabular}

\section{Efficacy of JCK-1233 in the Control of PWD by B. xylophilus on Pinus densiflora and $P$. thunbergii Seedlings}

The disease control efficacy of the JCK-1233 bacterial strain was evaluated against PWD on three- and four-year-old P. densiflora (black pine) and $P$. thunbergii (red pine) seedlings with an average height of $40 \mathrm{~cm}$ and an average root-collar calliper of $0.5 \mathrm{~cm}$. JCK-1233 were cultured in TSB at $30^{\circ} \mathrm{C}$ for $24 \mathrm{~h}$ with shaking at $150 \mathrm{rpm}$. Each culture was diluted using distilled water containing Tween $20(250 \mathrm{mg} / \mathrm{l})$ to a final concentration of $8 \times 10^{8}$ colony-forming units $(\mathrm{cfu}) / \mathrm{ml}$ using a UV-VIS spectrophotometer (UV-1601; Shimadzu Co., Kyoto, Japan). Black pine and red pine seedlings pre-treated with Tween 20 $(5 \mathrm{ml}, 250 \mathrm{mg} / \mathrm{l})$ per seedling were foliar sprayed twice with a JCK-1233 bacterial suspension (5 ml/seedling) at one-week interval. Distilled water containing Tween 20 (250 mg/l) was used as an untreated control. Emamectin benzoate $(20 \mathrm{mg} / \mathrm{ml})$ was supplied from Syngenta Korea (Seoul, South Korea) and used once as a positive control for treatment by trunk injection (100 $\mu \mathrm{l} /$ seedling). After one week from trunk injection with emamectin benzoate or the second treatment with the bacterial suspension, pine seedlings were inoculated with PWN as previously reported by Kwon et al. (2010). After making a small slit with a surface-sterilized knife in the stem of the seedlings, a small piece of absorbent cotton was inserted into the slit, and a water suspension of nematodes (2,000 nematodes/ $100 \mu \mathrm{l})$ was pipetted onto the absorbent cotton. The slits were then covered with Parafilm to prevent drying. PWD severity was evaluated according to the wilting and consequent discoloration area of the needles (Proença et al., 2010). The experiments were repeated twice in five replicates.

\section{In Vitro Nematicidal Activity of JCK-1233 Culture Filtrates Against B. xylophilus}

The nematicidal activity of JCK-1233 culture filtrates was evaluated testing their effect on the mortality of PWN $B$. xylophilus. Treatments were performed in 96 well tissue culture plates containing approximately $50 \mathrm{PWNs} /$ well. To prevent solution evaporation, the plates were covered and kept in the dark at $25^{\circ} \mathrm{C}$ with gentle shaking. Three days after exposure, the PWNs were moved to tap water and grouped into motile and immotile categories based on observations made under a light microscope (Leica DM IL LED; Leica Microsystems CMS $\mathrm{GmbH}$, Wetzlar, Germany) after pricking their bodies with a fine needle. PWNs that did not move and retained a stiff and straight body shape even after pricking with a needle were considered dead. TSB medium was used as a negative control. The experiment was repeated twice with triplicate. To analyze the nematicidal activity of JCK-1233 against PWNs, the mortality of PWNs was converted to percentage mortality and corrected using the formula of Schneider-Orelli (1947): Mortality $(\%)=[$ (mortality percentage in treatment - mortality percentage in the negative control $) /(100$ - mortality percentage in the negative control)] $\times 100$. The nematicidal activities of JCK1233 were evaluated analyzing the mortality of PWNs over a 
concentration range of 0.63 to $20 \%$. The experiments were repeated twice in triplicate.

\section{Molecular Identification of JCK-1233}

A JCK-1233 isolate showing induced resistance activity in pine seedlings was identified by $\operatorname{rec} A$ nucleotide sequence analysis. The genomic DNA of the JCK-1233 isolate was prepared using a DNeasy Blood and Tissue kit (Qiagen, Hilden, Germany) following the manufacturer's recommendations. PCR amplification of the $\operatorname{rec} A$ gene was performed using the universal bacterial primer pair recA-F (5'-GATCGTCA RGCAGSCYTWGAT - $\left.3^{\prime}\right)$ /recA-R (5' - T TWCCRACC ATAACSCCRAC- $3^{\prime}$ ) in a $20 \mu$ reaction mixture containing genomic DNA $(2 \mu \mathrm{l})$, primers $(1 \mu \mathrm{l}$ of each, $10 \mathrm{pM})$, sterilized distilled water $(16 \mu \mathrm{l})$, and Accupower ${ }^{\circledR}$ PCR premix $(1 \mu \mathrm{l})$ (Bioneer Corp., Daejeon, South Korea). The PCR conditions were 95 for $10 \mathrm{~min}$, followed by 35 cycles of 95 for $30 \mathrm{~s}, 49$ for $30 \mathrm{~s}$, and 72 for $1 \mathrm{~min}$, and then a final extension at 72 for $5 \mathrm{~min}$. The result from the recA sequencing was used to identify JCK1233 based on the National Center for Biotechnology Information (NCBI) blast database. Sequence alignment and phylogenetic analysis were performed using the neighborjoining (NJ) method with MEGA 6, with the number of bootstrap trials set to 1000 . The Kimura 2-parameter model was selected as the best model to construct the tree for NJ (Tamura et al., 2013).

\section{Extraction and Isolation of Potential Resistance Inducers From B. thuringiensis JCK-1233 Strain Cultures}

To find the chemicals giving inducible resistance to plants from the culture filtrates of $B$. thuringiensis JCK-1233, the strain was pre-cultured in in tryptic soy broth (TSB) medium overnight at 37 . Then, JCK-1233 was grown in TSB medium to an $\mathrm{OD}_{600}$ of 0.8 . The cultured broth of TSB-1233 (72 L) was condensed to $10 \mathrm{~L}$ on a rotary evaporator in vacuo at $40^{\circ} \mathrm{C}$. Then, the condensed broth was partitioned with $\mathrm{CH}_{2} \mathrm{Cl}_{2}$ to yield different fractions. The $\mathrm{CH}_{2} \mathrm{Cl}_{2}$ soluble fraction was subjected to silica gel column chromatography (CC) and eluted with $\mathrm{CH}_{2} \mathrm{Cl}_{2}-\mathrm{MeOH}$ (100:0 to 0:100, gradient, v/v), producing 13 fractions (C1-C13). Fraction $\mathrm{C} 7$ was further fractionated by silica gel CC and eluted with $\mathrm{CH}_{2} \mathrm{Cl}_{2}$-acetone $(20: 1, \mathrm{v} / \mathrm{v})$ to give eight sub-fractions (C7.1-C7.8). Sub-fraction C7.5 was purified by semipreparative RP-HPLC [Gilson Trilution System, Middleton, WI, USA; YMC Pak ODS-A column $(20 \times 250 \mathrm{~mm}, 5 \mu \mathrm{m}$ particle size), YMC Co., Kyoto, Japan; UV detection at $210 \mathrm{~nm}$ ] using $\mathrm{MeOH}$ and $\mathrm{H}_{2} \mathrm{O}$ in a 0.1\% TFA gradient (40:60-70:30, v/v) at a flow rate of $5 \mathrm{ml} / \mathrm{min}$ as a mobile phase. Fraction $\mathrm{C} 11$ was further fractionated by silica gel $\mathrm{CC}$ and eluted with $\mathrm{CH}_{2} \mathrm{Cl}_{2}$ acetone $(10: 1, \mathrm{v} / \mathrm{v})$ to produce seven sub-fractions (C11.1C11.7). Following a similar procedure to that used for C7.5, sub-fraction C11.4 was subjected to semi-preparative RP-HPLC using $\mathrm{MeOH}$ and $\mathrm{H}_{2} \mathrm{O}$ in a 0.1\% TFA gradient (50:50-70:30, v/v) at a flow rate of $5 \mathrm{ml} / \mathrm{min}$ as a mobile phase.

\section{Characterization of Potential Resistance Inducers Isolated From B. thuringiensis JCK-1233 Strain Cultures}

The optical rotations were measured using a Jasco P-1020 polarimeter (JASCO, Tokyo, Japan). The electrospray ionization (ESI) mass spectra were performed on an AGILENT 1100 LCMSD trap spectrometer (Agilent Technologies, Palo Alto, CA, USA). High-resolution electrospray ionization mass spectra (HRESI-MS) were obtained from an Agilent 6530 Accurate-Mass QTOF LC/MS system (Agilent technology, Santa Clara, CA, USA). NMR spectra were recorded with a Bruker $500 \mathrm{MHz}$ spectrometer (Bruker, Karlsruhe, Germany) using tetramethylsilane (TMS) as the internal standard. Silica gel (Merck, Darmstadt, Germany; 63 $-200 \mu \mathrm{m}$ particle size) and RP-18 (Merck, $75 \mu \mathrm{m}$ particle size) were used for CC. TLC was performed using Merck silica gel 60 $\mathrm{F}_{254}$ and RP-18 $\mathrm{F}_{254}$ plates. Preparative reversed-phase (RP)HPLC was performed using a Gilson Trilution System with an UV detector (UV/VIS-156) and a YMC Pak ODS-A column $(20 \times$ $250 \mathrm{~mm}, 5 \mu \mathrm{m}$ particle size, YMC Co., Kyoto, Japan). HPLC solvents were purchased from Burdick \& Jackson, USA.

\section{Effect of Foliar Spray and Trunk Injection of DPKs Produced by B. thuringiensis JCK-1233 Against PWD}

The disease control efficacy of diketopiperazines (DPKs) produced by JCK-1233 was evaluated against PWD on threeand four-year-old $P$. thunbergii (black pine) seedlings. Four DPKs isolated from JCK-1233 culture broth were diluted using distilled water containing Tween $20(250 \mathrm{mg} / \mathrm{l})$ to a working concentration of $1 \mathrm{mM}$ and then used for trunk injection and foliar spray treatments. For trunk injection, four DPKs (1 mM) and emamectin benzoate $(20 \mathrm{mg} / \mathrm{ml})$ containing $5 \% \mathrm{MeOH}$ were treated with $100 \mu \mathrm{l}$ per seedling. For foliar application, four DPKs ( $1 \mathrm{mM}, 5 \mathrm{ml}$ per seedling $)$ and JCK- 1233 culture $\left(\mathrm{OD}_{600}=\right.$ $0.8,5 \mathrm{ml}$ per seedling) were foliar sprayed on Tween 20 pretreated seedlings twice at one-week interval. For untreated controls, the same amount of sterile TSB in distilled water containing Tween $20(250 \mathrm{mg} / \mathrm{l})$ for foliar spray and $5 \%$ $\mathrm{MeOH}$ for trunk injection was applied. After one week from the second foliar spray and trunk injection treatments, pine seedlings were inoculated with PWN (2,000 nematodes/100 $\mu \mathrm{l})$. PWD severity was evaluated according to the wilting area of the seedling. The experiments were repeated twice in five replicates.

\section{Effect of B. thuringiensis JCK-1233 and cyclo-(L-Pro-L-Ile) on the Expression of Defense Related Genes In Vivo}

$P$. thunbergii (black pine) was used to analyze the effect on the defense related genes expression in pines. JCK-1233 was cultured to $\mathrm{OD}_{600}=0.8$ at 30 in TSB and then JCK-1233 bacterial suspension containing Tween 20 (250 mg/l, $5 \mathrm{ml}$ per seedling) used for foliar spray. The selected diketopiperazine, cyclo-(L-ProL-Ile), was diluted using distilled water containing Tween 20 
$(250 \mathrm{mg} / \mathrm{l})$ to a working concentration of $1 \mathrm{mM}$ and then used for foliar spray ( $5 \mathrm{ml}$ per Tween 20 pre-treated seedling twice at one-week interval). For untreated controls, the same amount of sterile TSB in distilled water containing Tween $20(250 \mathrm{mg} / \mathrm{l})$ was applied. After one week from the second treatment, pine seedlings were inoculated with PWN (2,000 nematodes/100 $\mu \mathrm{l})$. Three replicates were performed for each treatment.

At 1 day after the first treatment (1 DAT), 1 day after the second treatment/8 days after the first treatment (8DAT), and 1 day and 3 days after inoculation with PWN (1 DAI and 3 DAI), P. thunbergii total RNA was extracted from the pine needles using CTAB extraction buffer with elimination of high viscosity and excessive polysaccharides (Azevedo et al., 2003). Then, total RNA was further purified using IQeasy ${ }^{\mathrm{TM}}$ plus plant RNA extraction mini kit (iNtRON, Seongnam, South Korea), according to the manufacturer's recommendations. cDNA libraries were prepared from total pine needle RNA using oligo $(\mathrm{dT})$ primers and SuperScript ${ }^{\mathrm{TM}}$ IV reverse transcriptase (Invitrogen Inc., Carlsbad, CA, USA), according to the manufacturer's protocols. The PCR primers used in this study

(Table 1) were synthesized by Genotech (Daejeon, Korea).

Determination of relative mRNA expression was carried out in a real-time PCR detection system (Bio-Rad CFX 96; Bio-Rad Laboratories, Hercules, CA, USA). cDNA was analyzed using $\mathrm{iQ}^{\mathrm{TM}}$ SYBR Green supermix (Bio-Rad Laboratories) in a $20 \mu \mathrm{l}$ volume. The data were analyzed using BioRad CFX Manager Version 2.1. Relative fold changes in mRNA between treatments were determined based on the $\Delta \Delta \mathrm{CT}$ method after normalizing to the housekeeping gene elongation factor 1 alpha (Livak and Schmittgen, 2001). The samples were run in triplicate and averaged.

\section{Statistical Analysis}

The parameters measured in this study were designed to evaluate the efficacy of JCK-1233 and DPKs against PWN. The analyses were conducted separately for in vitro and in vivo experiments. All data were analyzed for homogeneity of variance using the SPSS statistical analysis software (version 21.0 for Windows; SPSS, Chicago, IL, USA). The data were expressed as means \pm standard error of replicates and evaluated by one-way analysis of variance (ANOVA). Statistical differences among treatments were determined according to Duncan's multiple-range test $(p<0.05)$.

\section{RESULTS}

\section{Primary Screening of Bacteria-Induced Resistance in Arabidopsis}

Five hundred and four bacterial strains were isolated from plants of five different regions in Korea. The isolated bacteria were screened for their potential resistance-inducing abilities using transgenic Arabidopsis plant lines containing the $\beta$-glucuronidase (GUS) construct fused to the $P R-1$ promoter, which are known to visualize the ability to elicit the SA signaling pathway when exposed to potential resistance inducers. After co- incubation of bacterial cultures with leaf discs from the PR-1pro:: GUS Arabidopsis line, 24 isolates out of 504 endophytic bacteria showed increased transcriptional GUS activity compared to that of the untreated control (Supplementary Data S1).

\section{Effect of the Selected Bacteria on PR-1 Transcript Expression in Pinus Calli}

Among the 24 selected bacterial strains from the previous $P R$ 1pro::GUS Arabidopsis assay, only 8 strains were shown in the pine callus assay to increase the expression of $P R-1$ at least 1.3fold compared to that in untreated controls (Table 2). Specifically, bacterial strain JCK-1233-treated calli showed the highest increase in $P R-1$ gene expression (3.59-fold compared to that in the untreated control). Based on these results, JCK-1233 was selected for further experiments as a potent candidate for the induction of resistance in pine trees.

\section{Efficacy of JCK-1233 in the Control of PWD by B. xylophilus on P. densiflora and P. thunbergii Seedlings}

Treatment with a JCK-1233 culture suspension significantly reduced PWD severity in nematode-inoculated $P$. densiflora and $P$. thunbergii seedlings (Figure 1). Disease severity in $P$. densiflora seedlings treated by foliar spray with a JCK-1233 culture suspension was significantly reduced compared to the control (24.2\% compared to $89.8 \%$ in treated and control samples, respectively). The control efficacy of JCK-1233 treatment was comparable to that of EB-treated seedlings, in which disease severity was $14.5 \%$ (Figure 1A). Moreover, wilting in EB and JCK-1233-treated P. densiflora seedlings appeared gradually, starting from 36 DAI with PWNs, while wilting in untreated controls of $P$. densiflora seedlings advanced rapidly starting from 20 DAI. Although the control efficacy of EB treatment $(83.9 \%)$ was slightly higher than that of JCK-1233 treatment, JCK-1233 treatment showed a significant control efficacy of $73.1 \%$ against PWD in $P$. densiflora seedlings (Figure 1C).

A similar control efficacy of JCK-1233 treatment was observed in $P$. thunbergii seedlings, in which disease severity reached $42.5 \%$, compared to $96.3 \%$ in untreated controls and

TABLE 2 | Relative transcription level of the SA marker PR1 in Pinus densiflora calli inoculated with the initially selected endophytic bacterial strains.

\begin{tabular}{lccc}
\hline Strain & $\boldsymbol{P R 1}$ & Strain & $\boldsymbol{P R 1}$ \\
\hline JCK-757 & $2.19 \pm 0.16$ & JCK-1229 & $1.08 \pm 0.42$ \\
JCK-758-1 & $0.94 \pm 0.41$ & JCK-1233 & $3.59 \pm 0.88$ \\
JCK-758-2 & $0.58 \pm 0.12$ & JCK-1266 & $0.73 \pm 0.19$ \\
JCK-761 & $1.30 \pm 0.14$ & JCK-1287 & $0.66 \pm 0.09$ \\
JCK-767 & $0.24 \pm 0.10$ & JCK-1288 & $1.49 \pm 0.34$ \\
JCK-947 & $0.82 \pm 0.13$ & JCK-1307 & $0.42 \pm 0.16$ \\
JCK-1005 & $0.67 \pm 0.09$ & JCK-1308 & $0.64 \pm 0.21$ \\
JCK-1180 & $2.04 \pm 0.49$ & JCK-1309 & $1.31 \pm 0.42$ \\
JCK-1182 & $0.55 \pm 0.12$ & JCK-1318 & $1.89 \pm 0.33$ \\
JCK-1187 & $2.25 \pm 0.68$ & JCK-1320 & $0.94 \pm 0.34$ \\
JCK-1217 & $0.75 \pm 0.11$ & JCK-1328 & $1.09 \pm 0.15$ \\
JCK-1222 & $0.12 \pm 0.02$ & JCK-1333 & $0.85 \pm 0.31$ \\
\end{tabular}

Data was presented as the mean \pm standard deviation of three biological replicates. 

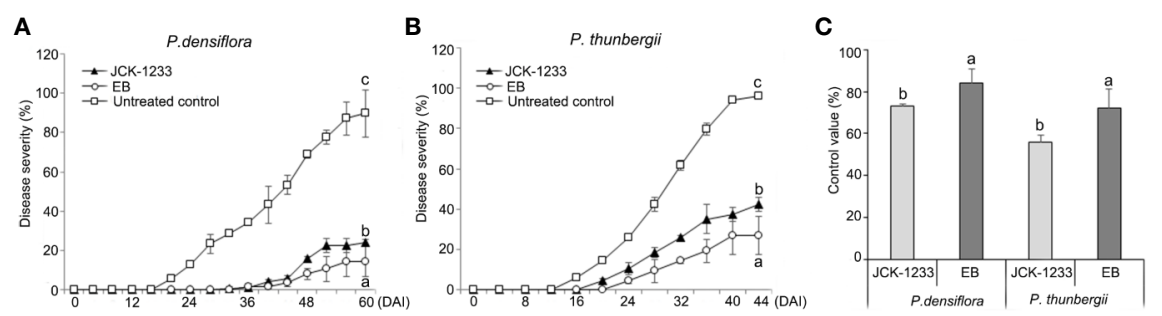

FIGURE 1 | Effect of the JCK-1233 culture broth against pine wilt disease caused by pine wood nematodes in pine seedlings. Disease severity after inoculation with pine wood nematodes in (A) red pine (Pinus densiflora) seedlings, and (B) black pine (Pinus thunbergii) seedlings. (C) Disease control efficacy at 28 days after inoculation (DAl) in $P$. densiflora and $P$. thunbergii seedlings. Data was represented as the mean and standard error of two runs with five replicates per run. Different lower case letters shown values that are significantly different $(p<0.05)$ level by Duncan's test.

$26.7 \%$ in EB treated seedlings (Figure 1B). In addition, wilting in untreated $P$. thunbergii appeared earlier (16 DAI) than in EBand JCK-1233-treated- $P$. thunbergii seedlings, in which wilting appeared gradually from 24 and 20 DAI, respectively. In agreement with the results on $P$. densiflora seedlings, JCK-1233 treatment also showed a significant control efficacy against PWD in $P$. thunbergii seedlings, although its control efficacy (55.8\%) was a little lower than that of EB treatment (72.3\%) (Figure 1C).

\section{In Vitro Nematicidal Activity of JCK-1233 Culture Suspensions Against B. xylophilus}

The effect of JCK-1233 culture suspensions on B. xylophilus juvenile mortality was determined at 3 days after exposure. There was no effect of JCK-1233 treatment on B. xylophilus juvenile mortality at the tested concentrations $(0.63-20 \%)$ compared to the TSB control treatment (0.8-1.9 and 2.3\%, respectively), whereas treatment with $\mathrm{EB}$ exhibited more than $99 \%$ mortality from a concentration of $0.33 \mu \mathrm{g} / \mathrm{ml}$ (Table 3). Therefore, JCK1233 does not seem to have a direct nematicidal activity against B. xylophilus.

\section{Molecular Identification of JCK-1233}

The selected bacterial isolate JCK-1233 was identified as $B$. thuringiensis based on BLAST and phylogenetic analyses of the

TABLE 3 | The in vitro nematicidal activity of JCK-1233 culture filtrates.

\begin{tabular}{lccc}
\hline Sample & Concentration & Mortality (\%) & STD \\
\hline Emamectin & 3 & $100.0 \mathrm{a}$ & 0.0 \\
Benzoate & 1 & $99.0 \mathrm{a}$ & 0.9 \\
$(\mu \mathrm{g} / \mathrm{ml})$ & 0.33 & $98.9 \mathrm{a}$ & 2.0 \\
& 0.11 & $64.0 \mathrm{~b}$ & 2.8 \\
& 0.04 & $51.3 \mathrm{c}$ & 5.3 \\
$\mathrm{JCK}-1233$ & 0.01 & $17.2 \mathrm{~d}$ & 1.5 \\
$(\%)$ & 20 & $1.9 \mathrm{e}$ & 2.0 \\
& 10 & $1.9 \mathrm{e}$ & 1.8 \\
& 5 & $0.8 \mathrm{e}$ & 1.3 \\
& 2.5 & $0.7 \mathrm{e}$ & 1.3 \\
TSB & 1.25 & $2.2 \mathrm{e}$ & 0.1 \\
& 0.63 & $0.8 \mathrm{e}$ & 1.3 \\
& - & $2.3 \mathrm{e}$ & 0.8
\end{tabular}

Each value represents the mean and standard deviation of two runs with three replicates per run. Different lower case letters shown values that are significantly different $(p<0.05)$ level by Duncan's test. amplified recA gene sequence (Figure 2). The amplified genes were registered in GenBank under the accession number MT024187. B. thuringiensis JCK-1233 was deposited in the KCCM (Korean Culture Center of Microorganisms, Seoul, Korea) as KCCM 14085BP.

\section{Extraction and Isolation of Putative Active Compounds From B. thuringiensis JCK- 1233 Strain Culture}

The condensed broth of JCK-1233 (10 L) was partitioned with $\mathrm{CH}_{2} \mathrm{Cl}_{2}$, yielding $\mathrm{CH}_{2} \mathrm{Cl}_{2}(2.3 \mathrm{~g})$ fractions. Using silica gel column chromatography (CC), the $\mathrm{CH}_{2} \mathrm{Cl}_{2}$ soluble fraction $(2.3 \mathrm{~g})$ was divided into 13 fractions $(\mathrm{C} 1-\mathrm{C} 13)$. Fraction C7 (510 mg) was further fractionated by silica gel CC and eluted with $\mathrm{CH}_{2} \mathrm{Cl}_{2}$-acetone $(20: 1, \mathrm{v} / \mathrm{v})$ to give eight sub-fractions (C7.1-C7.8). Sub-fraction C7.5 (253.5 mg) was purified by semi-preparative RP-HPLC using $\mathrm{MeOH}$ and $\mathrm{H}_{2} \mathrm{O}$ in a $0.1 \%$ TFA gradient (40:60-70:30, v/v) at a flow rate of $5 \mathrm{ml} / \mathrm{min}$ as a mobile phase to give compounds $2(40 \mathrm{mg})$ and $3(55 \mathrm{mg})$. Fraction C11 (255 mg) was fractionated by silica gel CC and eluted with $\mathrm{CH}_{2} \mathrm{Cl}_{2}$-acetone $(10: 1, \mathrm{v} / \mathrm{v})$ to produce seven subfractions (C11.1-C11.7). Following a similar procedure to that used for C7.5, sub-fraction C11.4 (140 mg) was subjected to semi-preparative RP-HPLC using $\mathrm{MeOH}$ and $\mathrm{H}_{2} \mathrm{O}$ in a $0.1 \%$ TFA gradient (50:50-70:30, v/v) at a flow rate of $5 \mathrm{ml} / \mathrm{min}$ as a mobile phase to give compounds $1(5.5 \mathrm{mg})$ and $4(5.0 \mathrm{mg})$.

\section{Characterization of Potential Resistance Inducers Isolated From B. thuringiensis JCK-1233 Strain Culture}

The presence of the DKP ring system in compounds 1-4 was evident from the characteristic carbon chemical shifts of two amide and carbonyl groups $\left(\delta_{\mathrm{C}} 166.6-172.6 \mathrm{ppm}\right)$, and proton chemical shifts of the two methine residues $\left(\delta_{\mathrm{H}} 3.63-4.45 \mathrm{ppm}\right)$ (Supplementary Data S2) (Jayatilake et al., 1996; Fdhila et al., 2003). The evidence of proline as one of the components of DKP (compounds 1-3) was deduced from the presence of three broad methylene multiplets $\left(\delta_{\mathrm{H}} 1.25-3.65 \mathrm{ppm}\right)$ in these compounds. Based on the analysis of 1-dimensional NMR data, COSY correlations and literature values, valine, isoleucine, and phenylalanine were identified as the second amino acid residue 


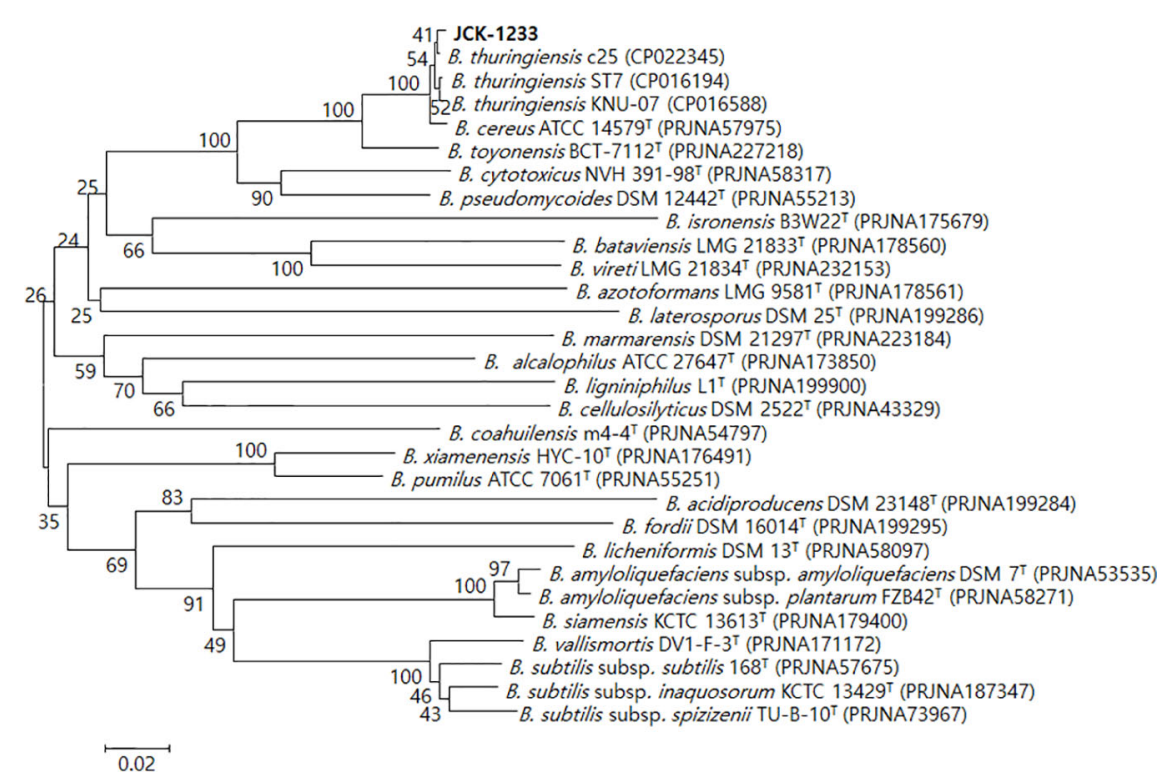

FIGURE 2 | Phylogenetic tree derived from a distance analysis of recA gene sequences in JCK-1233. The sequences were aligned using MEGA 6.0 software. The phylogenetic tree was constructed using the neighbor-joining (NJ) method with bootstrap analysis (1,000 trials). The selected strain was identified as Bacillus thuringiensis, which was separated in an exclusive cluster. Bars indicate the percentage of sequence divergence. T represents the type strains.

in compounds 1-3, respectively (Jayatilake et al., 1996; Campo et al., 2009; Li et al., 2012; Ding et al., 2013; Jiang and Yang, 2013), while in compound 4 it was the combination of leucine and valine (Ding et al., 2013). The configuration of the DKPs was determined by analysis of the NOESY spectrum and comparison with the optical rotations in the literature. In addition, in the NOESY spectrums, the NOE interactions between H-6 and H-9 observed in compounds 2 and 3, but not in compound 1, indicated that these two methine protons have the same orientation in compounds 2 and 3, and a different orientation in compound 1 . Based on the above analysis and combined with the positive optical rotation values of compounds 1 , and the negative optical rotation values of compounds 2 and 3 , the structures of compounds 1-3 were elucidated as cyclo-(D-ProL-Val) (Jayatilake et al., 1996; Shigemori et al., 1998; Fdhila et al., 2003; Campbell et al., 2009), cyclo-(L-Pro-L-Ile) (Jayatilake et al., 1996; Fdhila et al., 2003), and cyclo-(L-Pro-L-Phe) (Jayatilake et al., 1996; Fdhila et al., 2003), respectively (Figure 3). By a similar analysis, the structure of compound 4 was determined as cyclo-(L-Leu-L-Val) (Ding et al., 2013).

cyclo-(D-Pro-L-Val) (compound 1). Yellowish oil. $[\alpha] D^{23}+43.8$ (c 0.1, MeOH). ${ }^{1} \mathrm{H}$ NMR (500 MHz, $\left.\mathrm{CD}_{3} \mathrm{OD}\right): \delta 4.26(1 \mathrm{H}, \mathrm{m}, \mathrm{H}-7)$, $3.63(1 \mathrm{H}, \mathrm{m}, \mathrm{H}-9), 3.65,3.51$ (each $1 \mathrm{H}, \mathrm{m}, \mathrm{H}-3), 2.37,1.96$ (each $1 \mathrm{H}$, m, H-5), 2.17 (1H, m, H-10), 2.04, 1.91 (each 1H, m, H-4), $1.05(3 \mathrm{H}$, $\mathrm{d}, J=7.0, \mathrm{H}-11), 1.02(3 \mathrm{H}, \mathrm{d}, J=7.0, \mathrm{H}-12) .{ }^{13} \mathrm{C} \mathrm{NMR}(125 \mathrm{MHz}$, $\mathrm{CD}_{3} \mathrm{OD}$ ): $\delta 171.5$ (C-7), 168.1 (C-1), 64.5 (C-9), 59.8 (C-6), 46.8 (C3), 34.5 (C-10), 30.4 (C-5), 23.0 (C-4), 19.5 (C-11), 18.5 (C-12). HRESI-MS $m / z$ 197.1283 $[\mathrm{M}+\mathrm{H}]^{+}$(calcd for $\mathrm{C}_{10} \mathrm{H}_{17} \mathrm{~N}_{2} \mathrm{O}_{2}, 1972.1290$ ).

cyclo-(L-Pro-L-Ile) (compound 2). Yellowish oil. $[\alpha] D-25.5$ (c $0.14, \mathrm{MeOH}) .{ }^{1} \mathrm{H}$ NMR $\left(500 \mathrm{MHz}, \mathrm{CD}_{3} \mathrm{OD}\right): \delta 4.22(1 \mathrm{H}, \mathrm{m}, \mathrm{H}-$ 6), 4.10 (1H, m, H-9), 3.52-3.59 (2H, m, H-3), 2.34, 1.96 (each $1 \mathrm{H}$, m, H-5), 2.20 (1H, m, H-10), 2.04, 1.95 (each 1H, m, H-4), 1.47, 1.34 (each $1 \mathrm{H}, \mathrm{m}, \mathrm{H}-11), 1.10(3 \mathrm{H}, \mathrm{d}, J=7.0, \mathrm{H}-13), 0.96(3 \mathrm{H}, \mathrm{t}, J=7.5$, $\mathrm{H}-12) .{ }^{13} \mathrm{C}$ NMR (125 MHz, CD $\left.\mathrm{OD}\right): \delta 172.6$ (C-7), 167.6 (C-1), 60.0 (C-6), 61.3 (C-9), 46.2 (C-3), 37.1 (C-10), 29.6 (C-5), 25.5 (C11), 23.3 (C-4), 15.6 (C-13), 12.7 (C-12). HRESI-MS m/z 211.1443 $[\mathrm{M}+\mathrm{H}]^{+}$(calcd for $\mathrm{C}_{11} \mathrm{H}_{19} \mathrm{~N}_{2} \mathrm{O}_{2}, 211.1447$ ).

cyclo-(L-Pro-L-Phe) (compound 3). Yellowish oil. $[\alpha] D^{23}-43.9$ (c 0.16, MeOH). ${ }^{1} \mathrm{H}$ NMR (500 MHz, CD $\left.3 \mathrm{OD}\right): \delta 7.32$ (2H, m, H-3', 5'), 7.30 (2H, m, H-2', 6'), 7.28 (1H, m, H-4'), 4.45 (1H, m, H-6), 4.07 (1H, m, H-9), 3.55, 3.34 (each $1 \mathrm{H}, \mathrm{m}, \mathrm{H}-3), 3.18(2 \mathrm{H}, \mathrm{t}, J=4.5$, H-10), 2.11, 1.27 (each 1H, m, H-5), 1.80 (2H, m, H-4). ${ }^{13} \mathrm{C}$ NMR (125 MHz, CD $\left.{ }_{3} \mathrm{OD}\right): \delta 171.0$ (C-7), 166.9 (C-1), 137.5 (C-1'), 131.1 (C-3', 5'), 129.5 (C-2', 6’), 128.1 (C-4'), 60.1 (C-9), 57.4 (C-6), 46.1 (C-3), 38.1 (C-10), 29.4 (C-5), 22.9 (C-4). HRESI-MS m/z 245.1295 $[\mathrm{M}+\mathrm{H}]^{+}$(calcd for $\left.\mathrm{C}_{14} \mathrm{H}_{17} \mathrm{~N}_{2} \mathrm{O}_{2}, 245.1290\right)$.

cyclo-(L-Leu-L-Val) (compound 4). White amorphous powder. $[\alpha] D-38.1$ (c $0.15, \mathrm{MeOH}) .{ }^{1} \mathrm{H}$ NMR $(500 \mathrm{MHz}$, $\left.\mathrm{CD}_{3} \mathrm{OD}\right): \delta 3.97(1 \mathrm{H}, \mathrm{m}, \mathrm{H}-3), 3.80(1 \mathrm{H}, \mathrm{m}, \mathrm{H}-10), 2.24(1 \mathrm{H}, \mathrm{m}$, H-11), 1.88 (1H, m, H-5), 1.77, 1.63 (each $1 \mathrm{H}, \mathrm{m}, \mathrm{H}-4), 1.08(3 \mathrm{H}, \mathrm{d}$, $J=7.0, \mathrm{H}-12), 1.00(3 \mathrm{H}, \mathrm{d}, J=6.5, \mathrm{H}-7), 0.98(3 \mathrm{H}, \mathrm{d}, J=7.0, \mathrm{H}-13)$, $0.97(3 \mathrm{H}, \mathrm{d}, J=6.5, \mathrm{H}-6) .{ }^{13} \mathrm{C}$ NMR $\left(125 \mathrm{MHz}, \mathrm{CD}_{3} \mathrm{OD}\right): \delta 171.4$ (C-8), 169.8 (C-1), 61.6 (C-10), 54.5 (C-3), 46.1 (C-4), 33.8 (C-11), 25.4 (C-5), 23.7 (C-7), 21.9 (C-6), 19.4 (C-12), 17.9 (C-13). HRESIMS $m / z 213.1611[\mathrm{M}+\mathrm{H}]^{+}$(calcd for $\mathrm{C}_{11} \mathrm{H}_{21} \mathrm{~N}_{2} \mathrm{O}_{2}, 213.1603$ ).

\section{Effect of Foliar Spray and Trunk Injection of DPKs Produced by B. thuringiensis JCK-1233 Against PWD}

The effect of trunk injection and foliar spray with four DPKs produced by $B$. thuringiensis JCK-1233, cyclo-(D-Pro-L-Val), cyclo-(L-Pro-L-Ile), cyclo-(L-Pro-L-Phe), and cyclo-(L-Leu-L- 
A

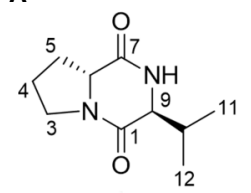

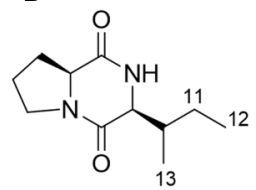

C<smiles>Cc1ccc(CC2NC(=O)C3CCCN3C2=O)cc1</smiles>

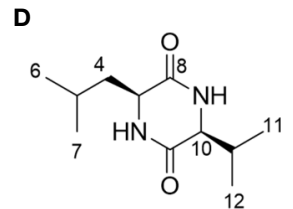

FIGURE 3 | Structural analyses of the isolated diketopiperazines from Bacillus thuringiensis JCK-1233. (A) cyclo-(D-Pro-L-Val), (B) cyclo-(L-Pro-L-Ile), (C) cyclo-(LPro-L-Phe), and (D) cyclo-(L-Leu-L-Val).

Val), on PWD control was determined in nematode-inoculated P. thunbergii seedlings 21 and 28 days after inoculation. Both trunk injection and foliar spray with a JCK-1233 culture filtrate or the four DPKs showed efficacy in reducing the severity of PWD in nematode-inoculated P. thunbergii seedlings (Figure 4). For trunk injection, the disease severity after treatment with compounds cyclo-(D-Pro-L-Val), cyclo-(L-Pro-L-Ile), cyclo-(LPro-L-Phe), and cyclo-(L-Leu-L-Val) were 30.0, 40.0, 51.7, and $25.8 \%$, respectively, after 21 days of inoculation, and progressed to $79.2,57.5,81.7$, and $51.7 \%$, respectively, after 28 days (Figure 4A). The disease control efficacy at 28 days after inoculation was excellent in cyclo-(L-Leu-L-Val) and cyclo-(L-Pro-L-Ile) (Figure 4B).

In foliar spray, disease severity after treatment with cyclo-(DPro-L-Val), cyclo-(L-Pro-L-Ile), cyclo-(L-Pro-L-Phe), and cyclo(L-Leu-L-Val) was 21.7, 28.3, 47.3, and 42.2\%, respectively, after 21 days of inoculation, and progressed to 71.7, 45.8, 75.8, and $65.8 \%$, respectively, after 28 days (Figure 4C). The disease severity and control value trends of the four DPKs upon foliar spray were similar to those observed upon trunk injection, except for cyclo-(L-Leu-L-Val) (Figure 4D). Specifically, after 28 days of inoculation, the disease control efficacy of cyclo-(L-Pro-L-Ile) by foliar spray (50.0\%) was the highest among the four compounds, and its disease control efficacy by trunk injection (37.3\%) against PWD was also as good as that of cyclo-(L-Leu-L-Val) (33.7\%), which showed the highest efficacy when trunk injected (Figures 4C, E).

\section{Effect of B. thuringiensis JCK-1233 and the Selected Bacterial Active Compound on the Expression of Defense Related Genes In Vivo}

The effect of foliar spray with either B. thuringiensis JCK-1233 or the bioactive compound cyclo-(L-Pro-L-Ile) was tested on the expression of defense-related genes in pine seedlings. The relative expression level of $P R-1$ gene was higher at 1 DAT with JCK-1233 and cyclo-(L-Pro-L-Ile) treatment (4.64-fold and 3.36 -fold increase, respectively) compared to that in untreated control (Figure 5A). At 1 DAI with PWN, 6.84-fold and 6.58fold increases in expression were observed in JCK-1233 and cyclo-(L-Pro-L-Ile) treated seedlings, respectively, compared to the untreated control at 1 DAT. However, untreated control seedlings showed a dramatic increase (16.40-fold) in $P R-1$ gene expression at $1 \mathrm{DAI}$ with PWN. The relative expression levels of
PR-2, $P R-3, P R-4, P R-5, P R-9, P d B G L 2$, and $P d P R-4$ also showed a similar pattern to that of $P R-1$ (Figures 5A, B).

On the contrary, the expression of $P R-10$ in the untreated control at 1 DAI only increased 4.42 -fold compared to that before inoculation, which was similar to the expression after JCK-1233 and cyclo-(L-Pro-L-Ile) treatments at the same time point. Moreover, unlike the expression of most pathogenesisrelated genes, including $P R-1$, the expression of $P R-10$ in JCK1233 and cyclo-(L-Pro-L-Ile) treated plants after 8 days treatment was markedly enhanced (13.57-fold and 13.00-fold, respectively). The expression level of $P R-6$ increased markedly at $1 \mathrm{DAI}$ and did not significantly differ between the untreated control (9.63fold), JCK-1233 treated (8.27-fold), and cyclo-(L-Pro-L-Ile) treated (8.49-fold) plants. In addition, after treatment and before nematode inoculation (at 1 DAT and 8 DAT), JCK1233 and cyclo-(L-Pro-L-Ile) treated plants showed a significant increase in the $P R-6$ expression level compared to that in untreated plants (Figure 5A).

These results suggest that $B$. thuringiensis JCK-1233 and cyclo-(L-Pro-L-Ile) enhance the expression of some pathogenesis-related genes in pine plants. However, such enhancement is lower than that produced in nematodeinoculated untreated control plants, except for PR-6 and PR-10 genes, indicating that the pathogenesis-related genes evaluated in this study may induce resistance against PWN in a different manner than the general hyposensitive reaction known to occur during SAR.

\section{DISCUSSION}

In this study, B. thuringiensis JCK-1233 was selected among 504 isolated bacteria for its ability to induce systemic resistance and suppress the severity of PWD. A DPK cyclo-(L-Pro-L-Ile) was identified as a bioactive compound from the selected strain and was shown to induce systemic resistance in pine calli and seedlings. Foliar treatment with the selected strain or the identified compound resulted in a significant reduction in the severity of PWD in inoculated pine seedlings. In general, foliar application using a biocontrol agent or its culture metabolite could represent a less expensive and more applicable approach compared to trunk injection with conventional chemical nematicides in largescale operations and mountainous forests with poor access. 
A

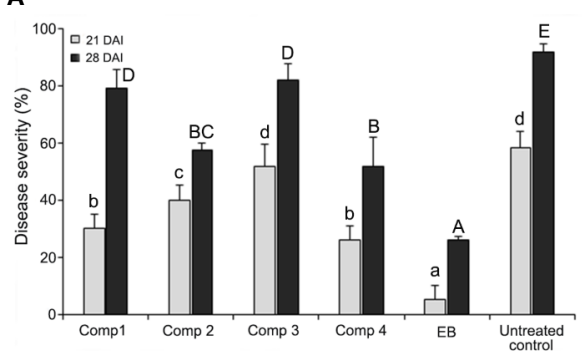

B

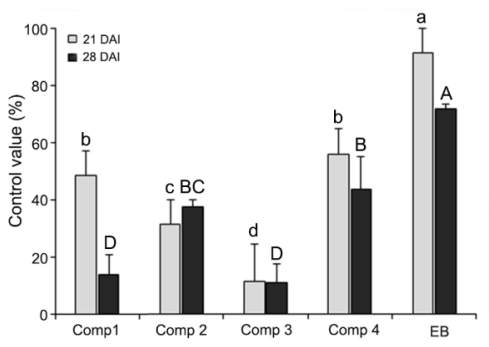

C

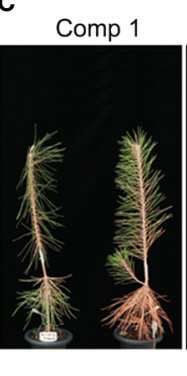

D

Comp 2

Comp 3
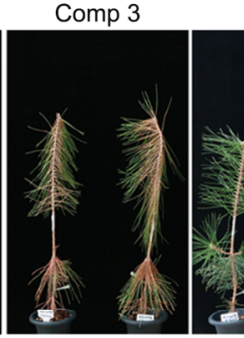

Comp 4

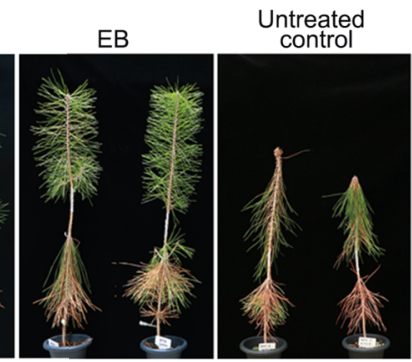

E
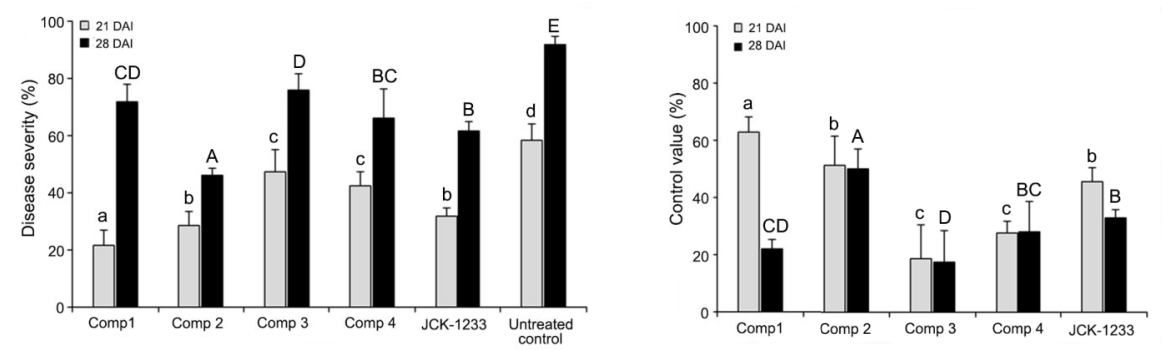

$\mathbf{F}$

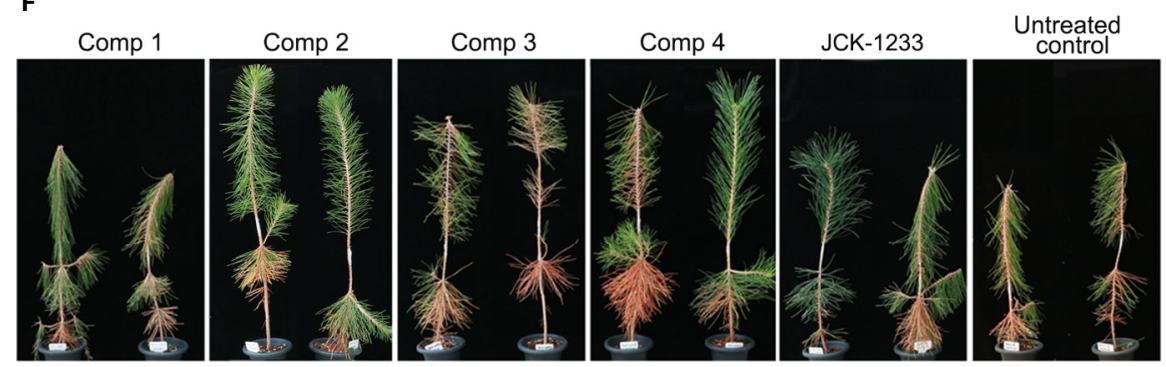

FIGURE 4 | Effect of trunk injection and foliar spray treatments with diketopiperazines on pine wilt disease (PWD). (A) Disease severity and (B) disease control efficacy of diketopiperazines against PWD at 21 and 28 days after inoculation (DAI) by trunk injection. (C) Photographs of the PWD wilting symptoms on pine seedlings treated with diketopiperazines by trunk injection at 28 DAI. (D) Disease severity and (E) disease control efficacy of diketopiperazines against PWD at 21 and 28 DAl by foliar spray. (F) Photographs of the PWD wilting symptoms on pine seedlings treated with diketopiperazines by foliar spray at 28 DAl. Comp 1, cyclo(D-Pro-L-Val); Comp 2, cyclo-(L-Pro-L-Ile); Comp 3, cyclo-(L-Pro-L-Phe); Comp 4, cyclo-(L-Leu-L-Val); EB, emamectin benzoate as a positive control. Error bars represent standard deviation from five replicates. Data was represented as the mean and standard error of two runs with five replicates per run. Different lower and upper case letters shown values that are significantly different $(p<0.05)$ level by Duncan's test with data at 21 and 28 DAl, respectively.

Several DPKs were obtained from B. thuringiensis JCK-1233, including cyclo-(D-Pro-L-Val), cyclo-(L-Pro-L-Ile), cyclo-(L-ProL-Phe), and cyclo-(L-Leu-L-Val). DPKs are among the most common peptide derivatives found in natural products as well as in processed foods and beverages. Of the identified DPKs, foliar application of cyclo-(L-Pro-L-Ile) efficiently reduced the incidence of PWD and resulted in the elevated expression of defense-related genes, similar to the effect of $B$. thuringiensis
JCK-1233 culture broth. Previous studies have reported the isolation of cyclo-(Pro-Ile) from Aspergillus terreus (mangroveassociated fungus), Bacillus pumilus, Callyspongia sp. (marine sponge), and Trichoderma citrinoviride (marine-derived fungus) (Shen et al., 2012; Brack et al., 2014; Chen et al., 2014; Zhang et al., 2014). Many studies have reported that DPKs exhibit various effects, including antibacterial, antifungal, antiviral, antitumor, and antitoxin activities (Yan et al., 2004; Noh et al., 

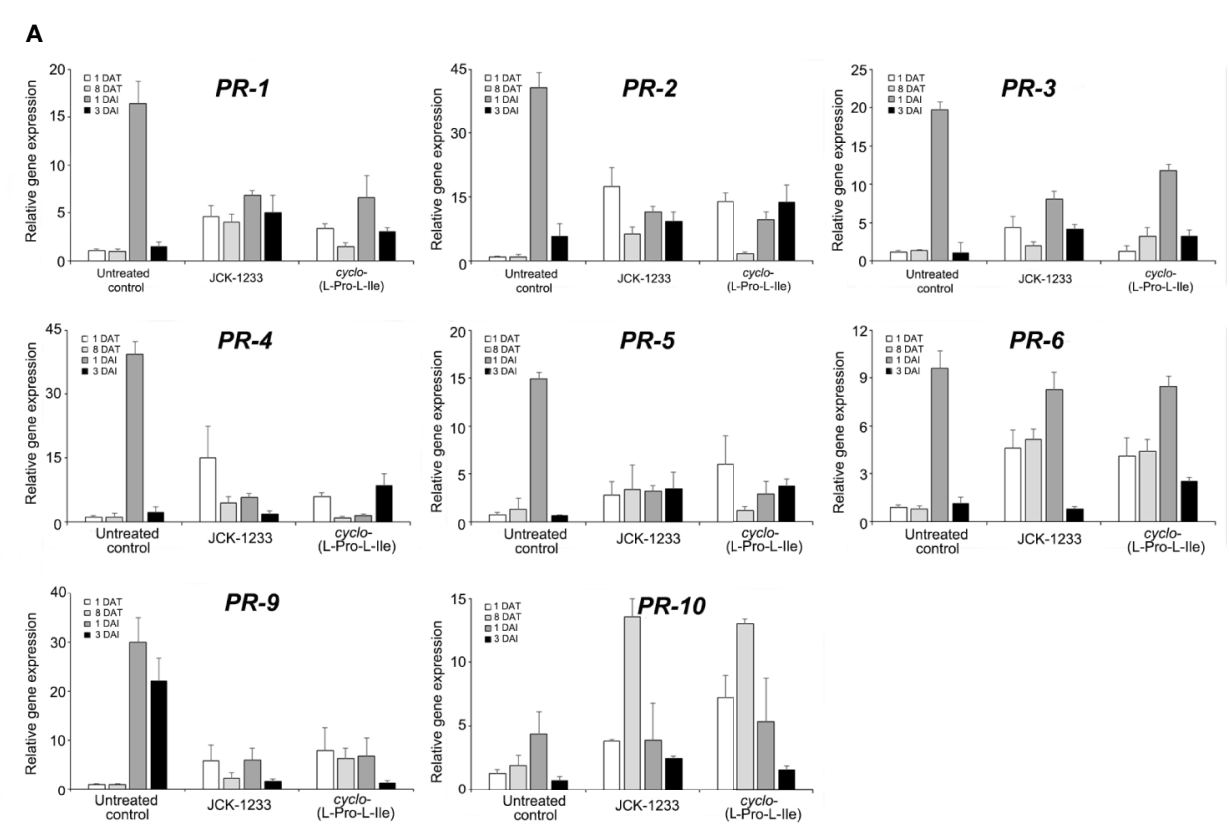

B
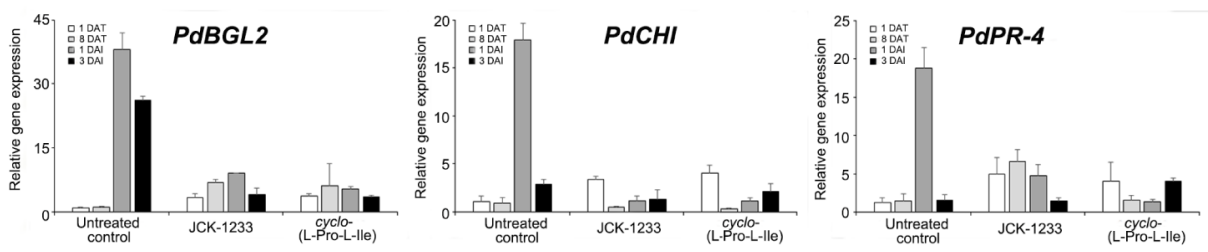

FIGURE 5 | Transcript levels of defense related genes in pine seedlings treated with Bacillus thuringiensis JCK-1233 and the bacterial active compound cyclo-( $\mathrm{L}-$ Pro-L-lle). The expression of pathogenesis-related (PR) genes amplified with primers oriented from black pine trees (Pinus thunbergii) (A) and red pine trees (Pinus densiflora) (B). Data was presented as the mean and standard error bars of three biological replicates.

2017). Plant growth promoting rhizobacteria (PGPRs) are also known to produce various DPKs that can induce resistance in plants (Noh et al., 2017). Although the plant signaling pathway mediated by DPKs is not clearly characterized yet, cyclo-(L-AlaL-Ile), cyclo-(L-Ala-L-Leu), and cyclo-(L-Leu-L-Pro) isolated from Bacillus vallismortis BS07 elicited disease resistance in Arabidopsis against bacterial infection (Noh et al., 2017). However, little is known about the biological functions of cyclo-(L-Pro-L-Ile).

It was reported that SAR is associated with the SA signaling pathway, whereas ISR is mediated by the JA and ET signaling pathways (Van Loon et al., 1998). However, they share a lot of similarities both in the result and the mechanisms, and are interconnected by complex signaling networks and crosstalk phenomena (Pieterse et al., 2009; Niu et al., 2016). Several researches have also reported that PGPRs could trigger ISR by concurrently activating the SA- and JA-/ET-signaling pathways, and even activate SA-dependent SAR (De Meyer et al., 1999; Andreasson and Ellis, 2010; Niu et al., 2011; Niu et al., 2016). Song et al. (2017) reported that seed defense biopriming by rootassociated Bacillus gaemokensis PB69 exhibited combined transcriptional responses with the upregulation of SA, ET, and jasmonic acid signaling. Furthermore, B. cereus AR156 is a PGPR that installs ISR to Pseudomonas syringae pv. tomato in Arabidopsis and enhances SAR with increased PR-1 protein expression in plants (Niu et al., 2016). Therefore, we predicted that endophytic bacteria may be able to stimulate the $P R-1$ gene expression as well as resistance-inducing activities.

Since the molecular background of induced resistance mechanism in pine trees is not fully understood, we isolated resistance-inducing endophytic bacteria through mass screening using Arabidopsis seedlings of the PR-1pro::GUS line. Although $P R-1$ is the marker gene for Arabidopsis SAR and SA-induced defense, it is a good indicator involved in pathogen- or microbeassociated molecular pattern (PAMPs/MAMPs) recognition. The induced resistance mechanism in different plant species was evaluated based on $P R-1$ gene expression in Pinus calli after treatment with the endophytic bacteria that were selected based on their GUS activity in the PR-1pro::GUS Arabidopsis line. Here, we selected $B$. thuringiensis JCK-1233, which stimulated the expression of the PR-1 gene in Arabidopsis and pine calli.

SA-mediated SAR responses are directed against biotrophic pathogens, occurring after the hypersensitive response (HR), which is a highly specific interaction between a plant resistance 
protein and a pathogenic avirulent, leading to programmed cell death and pathogen growth arrest in the infected plant tissue (Glazebrook, 2005). However, this is literally the case of biotrophic pathogens, such as Peronospora parasitica, Erysiphe spp., and Pseudomonas syringae, not PWNs. Interestingly, the development of PWD caused by PWN B. xylophilus has been reported to be closely associated with the HR. HR as a part of the plant immune system is a successful strategy for the control of many potential pests and pathogens, but, in susceptible pine trees against PWNs, this same system causes pine death. Myers (1988) suggested that invasion and early migration of PWNs through tissues enforces a typical HR, such as parenchymal death, toxin production, and leakage of oleoresins and other materials into tracheids. With the rapid migration and propagation of PWNs, the HR spreads throughout the whole plant, and shortly after, susceptible pine trees die. Indeed, several studies in pines have shown a significant increase in the expression of resistance genes to virulent PWNs in susceptible pine trees (Hirao et al., 2012; Lee et al., 2019).

In $P$. thunbergii, the expression of $P R-1, P R-2, P R-3, P R-4, P R-$ 5 , and $P R-6$ was increased in susceptible trees but not in resistant trees after inoculation with PWNs (Hirao et al., 2012). In Pinus densiflora, inoculation of PWN also increased the expression of genes involved in the defense response, such as PR proteins (Lee et al., 2019). Consistent with these results, we observed a marked rise in the expression levels of $P R-1, P R-2, P R-3, P R-4, P R-5, P R-$ 9, $P d B G L, P d C H I$, and $P d P R-4$ in the untreated control compared to JCK-1233 or cyclo-(L-Pro-L-Ile) treatment after inoculation with PWNs. In our gene expression analysis using the susceptible species Pinus thunbergii, we observed that the multitude of PR genes were upregulated up to 15-41-fold at 1 day after infection with PWNs compared to before infection, indicating that the $\mathrm{HR}$ can occur rapidly in pine seedlings infected with PWNs. Importantly, the untreated control group developed an HR much faster than the B. thuringiensis JCK-1233 and cyclo-(L-Pro-L-Ile) treated groups. Therefore, if there are treatments that can inhibit the migration of PWNs and alleviate the HR during infection, they may be helpful to control PWD. Our results suggest that disease resistance in pine trees may be caused by a moderate hypersensitive reaction.

Fitness-defense balance is important in terms of plant resistance against pathogens (Hirao et al., 2012). It is reasonable to think that plants express their inducible defense only if the protection against pathogens outweighs the costs of the resistance. However, in susceptible pine trees, plants develop an intense HR against PWNs. Although susceptible pine trees are unable to overcome infection, they develop excessive resistance systems, losing their fitness-defense balance and eventually dying. Pine seedlings treated with either $B$. thuringiensis JCK1233 or its active compound DPK cyclo-(L-Pro-L-Ile) moderately increased expression of PR genes compared to that of the untreated control before and after inoculation with PWNs, suggesting that a moderate hypersensitive reaction can be a factor in their resistance against PWD. Although the exact mechanism behind the resistance induced by JCK-1233 and its active compound, DPK cyclo-(L-Pro-L-Ile), was not investigated, we hypothesize that it is involved in maintaining the fitnessdefense balance. In addition, when PWNs infect susceptible pine trees, JCK-1233 and its active compound DPK cyclo-(L-Pro-LIle) may elicit a resistance consisting of interconnected complex signaling networks and, consequently, result in a moderate hypersensitive reaction. Therefore, we emphasize the importance of future investigations using molecular biological analyses to determine the functional mechanisms involved in the moderate HR induced by endophytic bacteria or DPKs, especially in susceptible pine trees, such as $P$. thunbergii, $P$. koraiensis, $P$. densiflora, and $P$. pinaster.

Among the tested $P R$ genes, the expression patterns of $P R-6$ and $P R-10$ were different from those of other genes related to the $H R$, which were markedly expressed when susceptible pine trees were infected with PWNs. After inoculation with PWNs, there was no significant difference in the expression of $P R-6$ and $P R-10$ between the untreated and treated groups (Figure 5). Moreover, B. thuringiensis JCK-1233 and cyclo-(L-Pro-L-Ile) treated pine seedlings exhibited significantly higher expression levels of $P R-6$ and $P R-10$ than that in the untreated control before inoculation with PWN. PR-6 is known to be active in nematodes and insects, acting as a proteinase inhibitor (Devi et al., 2017). In plants, induced proteinase inhibitors often have putative proteinases targeted to the digestive tract of specific insect predators (Heitz et al., 1999). Thus, a protein fraction from soybean inhibited growth and proteolytic activity of the meal worm Tribolium confusum in vitro (Lipke et al., 1954). PR-10 was shown to be a ribonuclease-like protein acting against a digestive proteinase secreted by the root knot nematode Meloidogyne incognita, which results in a nematostatic condition in vitro (Andrade et al., 2010). Along the same lines, PR-10 is predicted to act as a proteinase against cellulases, $\beta$-1,3-glucanase, and pectate lyases secreted by PWNs (Kikuchi et al., 2004; Kikuchi et al., 2005; Kikuchi et al., 2006; Hirao et al., 2012). Although both PR6 and PR-10 are not potent nematicidal proteins, they might have a role in the suppression of PWN propagation and migration during the early infection stage, representing an element in the induced resistance theory, moderate HR, proposed in this study.

In summary, $B$. thuringiensis JCK-1233 was selected among 504 isolated bacterial strains for its possible pine systemic resistance-inducing activity against PWD. Although the selected $B$. thuringiensis JCK-1233 did not have a direct nematicidal effect, foliar treatment of pine seedlings resulted in a significant reduction in PWD severity to a level comparable to that of EB trunk injection. In addition, out of the four DPKs isolated from the selected strain, the activity of cyclo-(L-Pro-LIle) was considered to be a main factor involved in the induction of pine seedling resistance by $B$. thuringiensis JCK-1233. Foliar application with cyclo-(L-Pro-L-Ile) showed better control efficacy compared to trunk injection, as observed at 28 DAI with PWN. Foliar application has two major advantages; it can effectively control PWD at a low cost, and it can be applied in the management of PWD in forests or areas that are inaccessible to humans. Treatment with $B$. thuringiensis JCK-1233 or the bioactive compound, the DPK cyclo-(L-Pro-L-Ile), moderately 
enhanced the expression of various pathogenesis-related genes associated with plant immunity. As a result, a rapid and intense HR was suppressed, and a fitness-defense balance was adequately maintained. Based on our results, it may be possible to develop an eco-friendly agent for the control of PWD utilizing our proposed agent as an aerial application. This study could be the cornerstone for prospective studies on the induced resistance against PWD in susceptible pine trees worldwide.

\section{DATA AVAILABILITY STATEMENT}

The original contributions presented in the study are included in the article/Supplementary Material; further inquiries can be directed to the corresponding authors.

\section{AUTHOR CONTRIBUTIONS}

AP, S-IJ, Y-SS, and J-CK conceived this study. AP, S-IJ, HJ, JuK, $\mathrm{NK}, \mathrm{MH}, \mathrm{MM}$, JunK, CL, BM, Y-SS, and J-CK performed the

\section{REFERENCES}

Andrade, L. B. D. S., Oliveira, A. S., Ribeiro, J. K., Kiyota, S., Vasconcelos, I. M., de Oliveira, J. T. A., et al. (2010). Effects of a novel pathogenesis-related class 10 (PR-10) protein from Crotalaria pallida roots with papain inhibitory activity against root-knot nematode Meloidogyne incognita. J. Agr. Food Chem. 58, 4145-4152. doi: 10.1021/jf9044556

Andreasson, E., and Ellis, B. (2010). Convergence and specificity in the Arabidopsis MAPK nexus. Trends Plant Sci. 15, 106-113. doi: 10.1016/ j.tplants.2009.12.001

Azevedo, H., Lino-Neto, T., and Tavares, R. M. (2003). An improved method for high-quality RNA isolation from needles of adult maritime pine trees. Plant Mol. Biol. Rep. 21, 333-338. doi: 10.1007/BF02772582

Baermann, G. (1917). Eine einfache methode zur auffindung von Ancylostomum (Nematoden) larven in erdproben. Geneeskd. Tijdschr. Ned. Indie. 57, 131-137.

Bell, C. (2000). Fumigation in the 21st century. Crop Prot. 19, 563-569. doi: 10.1016/S0261-2194(00)00073-9

Bonifácio, L. F., Sousa, E., Naves, P., Inácio, M. L., Henriques, J., Mota, M., et al. (2014). Efficacy of sulfuryl fluoride against the pinewood nematode, Bursaphelenchus xylophilus (Nematoda: Aphelenchidae), in Pinus pinaster boards. Pest Manage. Sci. 70, 6-13. doi: 10.1002/ps.3507

Brack, C., Mikolasch, A., and Schauer, F. (2014). 2, 5-Diketopiperazines produced by Bacillus pumilus during bacteriolysis of Arthrobacter citreus. Mar. Biotechnol. 16, 385-395. doi: 10.1007/s10126-014-9559-y

Campbell, J., Lin, Q., Geske, G. D., and Blackwell, H. E. (2009). New and unexpected insights into the modulation of LuxR-type quorum sensing by cyclic dipeptides. ACS Chem. Biol. 4, 1051-1059. doi: 10.1021/cb900165y

Campo, V. L., Martins, M. B., da Silva, C. H., and Carvalho, I. (2009). Novel and facile solution-phase synthesis of 2, 5-diketopiperazines and O-glycosylated analogs. Tetrahedron 65, 5343-5349. doi: 10.1016/j.tet.2009.04.069

Chen, Y., Peng, Y., Gao, C., and Huang, R. (2014). A new diketopiperazine from South China Sea marine sponge Callyspongia sp. Nat. Prod. Res. 28, 1010-1014. doi: 10.1080/14786419.2014.903397

Chinnasri, B., Sipes, B., and Schmitt, D. (2006). Effects of inducers of systemic acquired resistance on reproduction of Meloidogyne javanica and Rotylenchulus reniformis in pineapple. J. Nematol. 38, 319-325.

De Meyer, G., Capieau, K., Audenaert, K., Buchala, A., Métraux, J.-P., and Höfte, M. (1999). Nanogram amounts of salicylic acid produced by the rhizobacterium Pseudomonas aeruginosa 7NSK2 activate the systemic acquired resistance pathway in bean. Mol. Plant Microbe In. 12, 450-458. doi: 10.1094/MPMI.1999.12.5.450 experiments. AP, S-IJ, CL, MM, BM, Y-SS, and J-CK analyzed the data. AP, S-IJ, MH, BM, Y-SS, and J-CK wrote the manuscript. All authors contributed to the article and approved the submitted version.

\section{FUNDING}

This research was supported by the National Institute of Forest Science, South Korea (FE0702-2016-11-2020).

\section{SUPPLEMENTARY MATERIAL}

The Supplementary Material for this article can be found online at: https://www.frontiersin.org/articles/10.3389/fpls.2020.01023/ full\#supplementary-material

Devi, E. L., Kumar, S., Singh, T. B., Sharma, S. K., Beemrote, A., Devi, C. P., et al (2017). "Adaptation strategies and defence mechanisms of plants during environmental stress," in Medicinal Plants and Environmental Challenges (Berlin, Germany: Springer). 359-413.

Ding, G.-Z., Liu, J., Wang, J.-M., Fang, L., and Yu, S.-S. (2013). Secondary metabolites from the endophytic fungi Penicillium polonicum and Aspergillus fumigatus. J. Asian Nat. Prod. Res. 15, 446-452. doi: 10.1080/10286020. 2013.780349

Fdhila, F., Vázquez, V., Sánchez, J. L., and Riguera, R. (2003). DDDiketopiperazines: antibiotics active against Vibrio anguillarum isolated from marine bacteria associated with cultures of Pecten maximus. J. Nat. Prod. 66, 1299-1301. doi: 10.1021/np030233e

Glazebrook, J. (2005). Contrasting mechanisms of defense against biotrophic and necrotrophic pathogens. Annu. Rev. Phytopathol. 43, 205-227. doi: 10.1146/ annurev.phyto.43.040204.135923

Heitz, T., Geoffroy, P., Fritig, B., and Legrand, M. (1999). "The PR-6 family: proteinase inhibitors in plant-microbe and plant-insect interactions," in Pathogenesis-related proteins in plants. Eds. S. K. Datta and M. Subbaratnam (Boca Raton, FL: CRC Press), 131-155.

Hirao, T., Fukatsu, E., and Watanabe, A. (2012). Characterization of resistance to pine wood nematode infection in Pinus thunbergii using suppression subtractive hybridization. BMC Plant Biol. 12, 13. doi: 10.1186/1471-2229$12-13$

Hoffmann-Sommergruber, K. (2002). Pathogenesis-related (PR)-proteins identified as allergens. Biochem. Soc Trans. 30, 930-935. doi: 10.1042/ bst0300930

Jayatilake, G. S., Thornton, M. P., Leonard, A. C., Grimwade, J. E., and Baker, B. J. (1996). Metabolites from an antarctic sponge-associated bacterium, Pseudomonas aeruginosa. J. Nat. Prod. 59, 293-296. doi: 10.1021/np960095b

Jefferson, R. A., Kavanagh, T. A., and Bevan, M. W. (1987). GUS fusions: $\beta$ glucuronidase as a sensitive and versatile gene fusion marker in higher plants. EMBO J. 6, 3901-3907. doi: 10.1002/j.1460-2075.1987.tb02730.x

Jiang, K., and Yang, S. X. (2013). "Chemical constituents from marine Streptomycete sp. S15," in Advanced Materials Research (Baech, Switzerland: Trans Tech Publications). 1275-1277.

Kikuchi, T., Jones, J. T., Aikawa, T., Kosaka, H., and Ogura, N. (2004). A family of glycosyl hydrolase family 45 cellulases from the pine wood nematode Bursaphelenchus xylophilus. FEBS Lett. 572, 201-205. doi: 10.1016/ j.febslet.2004.07.039

Kikuchi, T., Shibuya, H., and Jones, J. T. (2005). Molecular and biochemical characterization of an endo- $\beta$-1, 3-glucanase from the pinewood nematode 
Bursaphelenchus xylophilus acquired by horizontal gene transfer from bacteria. Biochem. J. 389, 117-125. doi: 10.1042/BJ20042042

Kikuchi, T., Shibuya, H., Aikawa, T., and Jones, J. T. (2006). Cloning and characterization of pectate lyases expressed in the esophageal gland of the pine wood nematode Bursaphelenchus xylophilus. Mol. Plant Microbe Interact. 19, 280-287. doi: 10.1094/MPMI-19-0280

Kloepper, J. W., and Ryu, C.-M. (2006). "Bacterial endophytes as elicitors of induced systemic resistance," in Microbial root endophytes. Eds. B. J. E. Schulz, C. J. C. Boyle and T. N. Sieber (Berlin, Germany: Springer-Verlag), 33-52.

Kosaka, H., Aikawa, T., Ogura, N., Tabata, K., and Kiyohara, T. (2001). Pine wilt disease caused by the pine wood nematode: the induced resistance of pine trees by the avirulent isolates of nematode. Eur. J. Plant Pathol. 107, 667-675. doi: 10.1023/A:1011954828685

Kuroda, K. (2008). "Defense systems of Pinus densiflora cultivars selected as resistant to pine wilt disease," in Pine Wilt Disease: A Worldwide Threat to Forest Ecosystems. Eds. M. Mota and P. Vieiral (Berlin, Germany: Springer), 313-320.

Kwon, T.-S., Song, M.-Y., Shin, S.-C., and Park, Y.-S. (2005). Effects of aerial insecticide sprays on ant communities to control pine wilt disease in Korean pine forests. Appl. Entomol. Zool. 40, 563-574. doi: 10.1303/aez.2005.563

Kwon, H. R., Choi, G. J., Choi, Y. H., Jang, K. S., Sung, N. D., Kang, M. S., et al. (2010). Suppression of pine wilt disease by an antibacterial agent, oxolinic acid. Pest Manage. Sci. 66, 634-639. doi: 10.1002/ps.1920

Lee, I. H., Han, H., Koh, Y. H., Kim, I. S., Lee, S.-W., and Shim, D. (2019). Comparative transcriptome analysis of Pinus densiflora following inoculation with pathogenic (Bursaphelenchus xylophilus) or non-pathogenic nematodes (B. thailandae). Sci. Rep. 9, 1-11. doi: 10.1038/s41598-019-48660-w

Li, X.-J., Zhang, Q., Zhang, A.-L., and Gao, J.-M. (2012). Metabolites from Aspergillus fumigatus, an endophytic fungus associated with Melia azedarach, and their antifungal, antifeedant, and toxic activities. J. Agric. Food Chem. 60, 3424-3431. doi: 10.1021/jf300146n

Lipke, H., Fraenkel, G., and Liener, I. E. (1954). Growth inhibitors. Effect of soybean inhibitors on growth of Tribolium confusum. J. Agr. Food Chem. 2, 410-414. doi: 10.1021/jf60028a003

Livak, K. J., and Schmittgen, T. D. (2001). Analysis of relative gene expression data using real-time quantitative PCR and the $2^{-\triangle \Delta C T}$ method. Methods 25, 402408. doi: $10.1006 /$ meth.2001.1262

Maehara, N., and Futai, K. (2000). Population changes of the pinewood namatode, Bursaphelenchus xylophilus (Nematoda: Aphelenchoididae), on fungi growing in pine-branch segments. Appl. Entomol. Zool. 35, 413-417. doi: 10.1303/ aez.2000.413

Mamiya, Y., and Enda, N. (1972). Transmission of Bursaphelenchus lignicolus (Nematoda: Aphelenchoididae) by Monochamus alternatus (Coleoptera: Cerambycidae). Nematologica 18, 159-162. doi: 10.1163/187529272X00395

Mota, M. M., Braasch, H., Bravo, M. A., Penas, A. C., Burgermeister, W., Metge, K., et al. (1999). First report of Bursaphelenchus xylophilus in Portugal and in Europe. Nematology 1, 727-734. doi: 10.1163/156854199508757.

Myers, R. F. (1988). Pathogenesis in pine wilt caused by pinewood nematode, Bursaphelenchus xylophilus. J. Nematol. 20, 236-244.

Narusaka, M., Abe, H., Kobayashi, M., Kubo, Y., Kawai, K., Izawa, N., et al. (2006). A model system to screen for candidate plant activators using an immuneinduction system in Arabidopsis. Plant Biotech. 23, 321-327. doi: 10.5511/ plantbiotechnology.23.321

Niu, D.-D., Liu, H.-X., Jiang, C.-H., Wang, Y.-P., Wang, Q.-Y., Jin, H.-L., et al. (2011). The plant growth-promoting rhizobacterium Bacillus cereus AR156 induces systemic resistance in Arabidopsis thaliana by simultaneously activating salicylate-and jasmonate/ethylene-dependent signaling pathways. Mol. Plant Microbe In. 24, 533-542. doi: 10.1094/MPMI-09-10-0213

Niu, D., Wang, X., Wang, Y., Song, X., Wang, J., Guo, J., et al. (2016). Bacillus cereus AR156 activates PAMP-triggered immunity and induces a systemic acquired resistance through a NPR1-and SA-dependent signaling pathway. Biochem. Bioph. Res. Co. 469, 120-125. doi: 10.1016/j.bbrc.2015.11.081

Noh, S. W., Seo, R., Park, J.-K., Manir, M. M., Park, K., Sang, M. K., et al. (2017). Cyclic dipeptides from Bacillus vallismortis BS07 require key components of plant immunity to induce disease resistance in Arabidopsis against Pseudomonas Infection. Plant Pathol. J. 33, 402-409. doi: 10.5423/ PPJ.OA.11.2016.0255
Nose, M., and Shiraishi, S. (2008). "Breeding for resistance to pine wilt disease," in Pine wilt disease (Tokyo, Japan: Springer). 334-350.

Ogura, R., Matsuo, N., Wako, N., Tanaka, T., Ono, S., and Hiratsuka, K. (2005). Multicolor luciferases as reporters for monitoring transient gene expression in higher plants. Plant Biotech. 22, 151-155. doi: 10.5511/plantbiotechnology.22.151

Ono, S., Tanaka, T., Watakabe, Y., and Hiratsuka, K. (2004). Transient assay system for the analysis of $P R-1 a$ gene promoter in tobacco BY-2 cells. Biosci. Biotechnol. Biochem. 68, 803-807. doi: 10.1271/bbb.68.803

Pieterse, C. M., Leon-Reyes, A., Van der Ent, S., and Van Wees, S. C. (2009). Networking by small-molecule hormones in plant immunity. Nat. Chem. Biol. 5, 308-316. doi: 10.1038/nchembio.164

Proença, D. N., Francisco, R., Santos, C. V., Lopes, A., Fonseca, L., Abrantes, I. M., et al. (2010). Diversity of bacteria associated with Bursaphelenchus xylophilus and other nematodes isolated from Pinus pinaster trees with pine wilt disease. PloS One 5, e15191-e15151. doi: 10.1371/journal.pone.0015191

Rohrbach, K. G., and Apt, W. J. (1986). Nematode and disease problems of pineapple. Plant Dis. 70, 81-87. doi: 10.1094/PD-70-81

Schneider-Orelli, O. (1947). Entomologisches praktikum: Einführung in die land-und forstwirtschaftliche Insektenkunde (Verlag Sauerländer Switzerland: Aarau).

Shen, Y., Zou, J., Xie, D., Ge, H., Cao, X., and Dai, J. (2012). Butyrolactone and cycloheptanetrione from mangrove-associated fungus Aspergillus terreus. Chem. Pharm. Bull. 60, 1437-1441. doi: 10.1248/cpb.c12-00616

Shigemori, H., Tenma, M., Shimazaki, K., and Kobayashi, J. I. (1998). Three new metabolites from the marine yeast Aureobasidium pullulans. J. Nat. Prod. 61, 696-698. doi: 10.1021/np980011u

Song, G. C., Choi, H. K., Kim, Y. S., Choi, J. S., and Ryu, C.-M. (2017). Seed defense biopriming with bacterial cyclodipeptides triggers immunity in cucumber and pepper. Sci. Rep. 7, 1-15. doi: 10.1038/s41598-017-14155-9

Tóth, Á. (2011). Bursaphelenchus xylophilus, the pinewood nematode: its significance and a historical review. Acta Biol. Szeged. 55, 213-217.

Takai, K., Suzuki, T., and Kawazu, K. (2003). Development and preventative effect against pine wilt disease of a novel liquid formulation of emamectin benzoate. Pest Manage. Sci. 59, 365-370. doi: 10.1002/ps.651

Tamura, K., Stecher, G., Peterson, D., Filipski, A., and Kumar, S. (2013). MEGA6: molecular evolutionary genetics analysis version 6.0. Mol. Biol. Evol. 30, $2725-$ 2729. doi: $10.1093 / \mathrm{molbev} / \mathrm{mst} 197$

Vallad, G. E., and Goodman, R. M. (2004). Systemic acquired resistance and induced systemic resistance in conventional agriculture. Crop Sci. 44, 19201934. doi: $10.2135 /$ cropsci2004.1920

Van Loon, L., Bakker, P., and Pieterse, C. (1998). Systemic resistance induced by rhizosphere bacteria. Annu. Rev. Phytopathol. 36, 453-483. doi: 10.1146/ annurev.phyto.36.1.453

Yan, P.-S., Song, Y., Sakuno, E., Nakajima, H., Nakagawa, H., and Yabe, K. (2004). Cyclo (L-leucyl-L-prolyl) produced by Achromobacter xylosoxidans inhibits aflatoxin production by Aspergillus parasiticus. Appl. Environ. Microbiol. 70, 7466-7473. doi: 10.1128/AEM.70.12.7466-7473.2004

Yano, S. (1913). Investigation on pine death in Nagasaki prefecture. SanrinKouhou 4, 1-14.

Yi, C. K., Byun, B. H., Park, J. D., Yang, S., and Chang, K. H. (1989). First finding of the pine wood nematode, Bursaphelenchus xylophilus (Steiner et Buhrer) Nickle and its insect vector in Korea. Res. Rep. For. Res. Ins. Seoul 38, 141-149.

Zhang, Q.-Q., Chen, L., Hu, X., Gong, M.-W., Zhang, W.-W., Zheng, Q.-H., et al. (2014). Novel cytotoxic metabolites from the marine-derived fungus Trichoderma citrinoviride. Heterocycles 89, 189-196. doi: 10.3987/COM-13-12874

Conflict of Interest: The authors declare that the research was conducted in the absence of any commercial or financial relationships that could be construed as a potential conflict of interest.

Copyright (๐ 2020 Park, Jeong, Jeon, Kim, Kim, Ha, Mannaa, Kim, Lee, Min, Seo and Kim. This is an open-access article distributed under the terms of the Creative Commons Attribution License (CC BY). The use, distribution or reproduction in other forums is permitted, provided the original author(s) and the copyright owner(s) are credited and that the original publication in this journal is cited, in accordance with accepted academic practice. No use, distribution or reproduction is permitted which does not comply with these terms. 